\title{
Estado, crisis y nuevos actores sociales en Centroamérica. El caso de El Salvador
}

\author{
Segundo Montes \\ Taller: "La cultura política y el estado en América Central". \\ (Maestría Centroamericana en Sociologia; \\ San José, 26-28 julio 1989)
}

Introducclón

Al ponerse de nuevo en marcha los mecanismos del proceso electoral en El Salvador, conclula mi análisis en enero de 1982 con los siguientes párrafos (Montes, 1982; 65-66):

"El problema fundamental que agobia a El Salvador, por consiguiente, seguirá sin resolverse en estas elecciones, porque no se lo plantea tan siquiera".

"Si no se plantea el problema en sus verdaderos términos, ni se aborda su realidad, no puede resolverse. Las elecciones, tal como han sido propuestas, dejarán intacto el problema fundamental en toda su agudeza, o la profundizarán y radicalizarán todavla más, hasta que uno de los polos obtenga la victoria sobre el otro, o hasta que ambos, tal vez agotados, pongan en común su parte de poder para salvar a la sociedad total, y para que el pueblo, único soberano, exprese su voluntad propia y decida su destino".

A siete anos y medio de aquellas afirmaciones, la historia parece haberles concedido bastante razón, no porque fueran intuiciones visionarias ni profeclas, sino que estaban sustentadas en el análisis de la correlación de fuerzas y en las condiciones exigidas por la democracia. Se han sucedido desde entonces cinco elecciones diversas, se han alternado distintos partidos y fuerzas políticas, se han ensayado modelos diferentes, y el problema continúa sin resolverse - tal vez en su punto 
más álgido. Pero también en el proceso han ido surgiendo, articulándose o desintegrándose nuevos actores sociales y políticos, como puede desprenderse del estudio analítico de los resultados electorales y de las circunstancias concomitantes. En el Anexo se ofrecen los resultados de las cinco elecciones, presentados de manera unitorme para una más fácil comparación de los datos a lo largo de esos años.

\section{Anállsis de los resultados}

Un primer dato que se puede extraer de los cuadros anexados es la tendencia decreciente en el número de votantes, que superó -según los datos oficiales - el millón y medio de concurrentes a las urnas, y que va declinando ano con año hasta la cifra de poco más de un millón en 1989. Este fenómeno es tanto más llamativo cuanto que tradicionalmente en El Salvador la concurrencia a las urnas ha sido muy elevada $\rightarrow$ por distintas razones, entre las que no hay que excluir la obligatoriedad y los posibles mecanismos de control de haber votado, a través de los documentos de identificación personal que deben ser marcados para evitar complicaciones civico-politicas o laborales, o incluso para no incurrir en la multa correspondiente. Además, las votaciones para elegir presidente siempre han atraido más votantes que las de diputados y alcaldes. Sin embargo, los datos oficiales de las elecciones de 1982 no son una base firme de comparación, dado que obedecen a una maniobra de fraude-intlación de votos proporcionales a los reales, con el fin de crear una campaña de legitimación-justificación del sistema, a la vez que de deslegitimación de la insurgencia armada (ECA, abril 1982: 233258; Boletín, marzo-abril 1982: 301-320).

Un segundo dato interesante es que la tasa "normal" de votos noválidos está en torno al 12\%, por lo que las "atipicas" de 1988 y 1989 deben ser explicadas. La incrementada en 1988, a nuestro juicio, reflejarla la voluntad positiva de una parte importante del electorado, que se ha empadronado, ha conseguido el carnet electoral, ha acudido a las urnas, de mostrar simultáneamente su inconformidad con la democracia formal, al no hallar en la gama de partidos políticos participantes ninguno que satisfaga sus aspiraciones y represente legitimamente sus interes, al mismo tiempo que el repudio expreso de los partidos contendientes que no han querido o no han podido resolver los problemas fundamentales del pais - aparte de la "tasa normal" de invalidantes de su voto, por distintos motivos. La disminuida tasa de 1989, en cambio, obedecerla a la actitud bastante generalizada en vastos sectores de la población, de frustración y desilusión frente a la posición de los partidos políticos contendientes, que prefirieron competir por la magra cuota de poder político antes que forzar la aceptación de la propuesta del FMLN 
de 23 de enero de 1989, por la que se comprometía a aceptar el resultado electoral si se postergaban las elecciones al 15 de septiembre y se cumplian otras condiciones que permitieran su participación directa o indirecta (Montes, 1989: 199-210) -esa interpretación se ve confirmada con la encuesta que el Instituto Universitario de Opinión Pública de la UCA (IUDOP) cursó después de las elecciones, en la que aparece que el $41 \%$ de los encuestados no fue a votar por distintas razones $(11 \%$ por el paro al transporte, $12.7 \%$ por falta de credibilidad en las elecciones, $36.5 \%$ por carencia de carnet o problema con los listados, $23.6 \%$ por entermedad - lo que más bien podria interpretarse como una excusa-. $12.4 \%$ por otras razones - IUDOP, mayo de 1989a).

Como consecuencia de lo anterior, la cantidad de votos válidos ha decrecido en los sucesivos años, para fijarse en poco más de novecientos mil en los dos últimos, lo que corresponde a poco más del $50 \%$ de los realmente posibles -por disponer del carnet electoral requerido para emitir el voto-, y apenas arriba del $40 \%$ de la cifra mínima de personas en edad de votar residentes en el pals (Montes, 1988: 175190: 199-209).

La aceptación que tiene cada uno de los partidos políticos para el electorado salvadoreño, con el transcurso de los ańos, merece un análisis detallado, tanto para la globalidad del pals, como para los votos de cada uno de los departamentos. Tomaremos en cuenta no la cantidad absoluta de votos - no tanto porque varía en función de los emitidos, cuanto por el hecho de que los del primer afio, 1982, carecen de toda confiabilidad-, sino los porcentajes de votos válidos obtenidos por cada partido en los diferentes anos y elecciones.

El partido demócrata cristiano (PDC) incrementa su porcentaje, desde apenas arriba del $40 \%$ en 1982 , hasta superar el $52 \%$ en 1985 , logrando el cúlmen de su popularidad, para declinar en las dos últimas elecciones hasta el 35\%, o poco más; la supuesta constante cantidad de votantes en las tres primeras, se demumba hasta un tercio de millón de votos válidos. Si ello es consecuencia del fracaso del partido en la gestión pública, o del desgaste en la misma, si se ha debido a un numeroso "voto de castigo" o a cualquier otra causa múltiple, o dificil de medir, la realidad es que una cantidad considerablemente menor de ciudadanos - tanto en valores absolutos como porcentuales- se inclina a depositar su confianza en la gestión política de dicho partido para ser representados por él y para esperar del mismo la solución a los más graves y apremiantes problemas del pais y de ellos mismos.

El partido Alianza Republicana Nacionalista (ARENA), en cambio, mantiene un porcentaje de votos muy constante en las tres primeras 
elecciones, pero incrementa su representación porcentual considerablemente en las dos últimas - asl como la cantidad absoluta de votos obtenidos. Si en la de 1988 se pudiera atribuir buena parte del incremento al "voto de castigo", en la de 1989 hay que buscarle otra interpretación, debida no tan sólo al trabajo de bases y de cuadros realizado en el último período, ni sólo a la campana electoral, sino también a espectativas de una cantidad creciente de población de que a través de un gobierno de dicho partido pueda abordar mejor y más eficientemente los problemas principales y encontrarles solución más acertada.

El Partido de Conciliación Nacional (PCN) -a diferencia de partidos oficiales de otras épocas, que desaparecen con el gobierno derrocado por un golpe de estado- se mantiene en las dos primeras pruebas electorales con algo más del $19 \%$ de los votos válidos, baja a menos de la mitad en las dos siguientes, para reducirse a poco más del $4 \%$ en las últimas. Todo ello pareceria indicar un constante declinar en su arrastre popular, no sólo por las modificaciones de su linea política, los cambios en la cúpula del partido, sino también por la polarización creciente de la sociedad salvadorena, que opta preferentemente por alguno de los partidos mayores y con más posibilidades políticas, o por la abstención -que no necesariamente significa una opción consciente y positiva por partidos o movimientos fuera de la competencia legítima.

El resto de partidos menores, por último, -además de ser en conjunto minoritarios respecto a los tres mayores, a excepción de dos votaciones- muestran una tendencia constante a su disminución proporcional, de apenas arriba del $11 \%$ hasta el $6 \%$ en la última votación. Si se exceptúa la elección presidencial de marzo de 1989, rodeada de circunstancias peculiares, como la frustración de gran parte de la población al no haberse postergado las elecciones y con ello haber vislumbrado el cese del conflicto ammado $-60.1 \%$ de la población estaba de acuerdo con postergar las elecciones, y sólo el $32.5 \%$ se oponía a ello (IUDOP, No. 20, marzo 1989: 17-18) -, agregado a la instrucción de última hora por parte del FMLN en el sentido de abstenerse de ir a votar, lo que podría explicar en parte el pronunciado decremento; la tendencia a la disminución en el porcentaje de representatividad es constante, lo que serla un indicador de la creciente polarización de la sociedad salvadorena. El hecho de que en las elecciones de marzo de 1989 se ofreciera una nueva alternativa, con la participación de la Convergencia Democrática (CD), que pudiera haber atraido una parte de la gran masa de abstenciones en las anteriores, se vio neutralizado por las circunstancias que ya se han indicado. Más adelante se ana- 
lizará la conformación ideológico-política de los partidos aglutinados en la categoria de "otros".

Si se comparan los resultados obtenidos por cada uno de los tres partidos mayores, por departamento, en cada una de las elecciones, el PDC superó a ARENA en 1982 en todos los departamentos, menos en Usulután, Cuscatlán y Cabanas; en las de 1984, recuperó la mayoría de Usulután; en 1985 sólo en Cuscatlán ARENA lo superó; en 1988 ARENA obtuvo más votos en todos los departamentos, a excepción de La Unión, Chalatenango y Morazán, en los que el PDC alcanzó una escasa superioridad; y en 1989 únicamente en La Unión el PDC obtuvo una insignificante mayorla. EI PCN en 1982 superó a ARENA en La Unión y en San Vicente, y a ambos partidos en Cabafias; en 1984 obtuvo más votos que ARENA en San Miguel, Usulután y Morazán, y más que los otros dos partidos en La Unión; en 1985 sólo superó a ARENA en La Unión; y en las siguientes votaciones se mantuvo por debajo de los dos partidos mayores. Al buscar alguna tendencia en estos datos, lo más que se puede concluir es la consistencia de votos para el PCN - en las primeras elecciones - en el departamento de La Unión, en menor grado en el de Cabañas, pero también la pérdida de base social en ellos y en los demás departamentos. En cuanto al PDC, parece también deducirse en qué departamentos tiene menos base social o es más débil: Cuscatlán y Cabanas, ciertamente, y en menor grado Usulután.; la consistencia en La Unión, por el contrario, mostraría una buena organización de base, y tal vez un trasvase de votos del PCN hacia el PDC. Por lo que se refiere al partido ARENA, en cambio, los resultados muestran un crecimiento constante en todos los departamentos, con la salvedad de La Unión, en donde se mantiene escasamente por debajo del PDC. Dada la diversidad de características en los departamentos de "excepción", no se perciben tendencias claras, vinculadas ni con la conflictividad de la zona, ni con la composición étnica y demográfica, social o de otra índole, como tampoco en la riqueza del suelo, tipo de cultivo y estructura de tenencia o relaciones de trabajo. La explicación habrá que buscarla más bien por la organización de cuadros del partido correspondiente y el trabajo de base, asi como en la satisfacción-frustración de necesidades y aspiraciones, o en las espectativas generadas hacia un cambio frente a la irresolución de las mismas o a su empeoramiento en las dos variables fundamentales que la población sefiala persistentemente en todas las encuestas de opinión: el problema económico y la guerra-violencia-represión (IUDOP, passim).

\section{II. fuerzas soclales aglutinadas detras de cada partido}

Una cosa es la ideología y los intereses de clase que propugna cada 
uno de los partidos politicos, y otra cosa la base social que to sustenta, así como la preferencia por él de parte del electorado en una oferta limitada de partidos contendientes. Intentaré presentar brevemente ambos aspectos para cada uno de los partidos.

\subsection{ARENA}

EI partido ARENA, desde su comienzo, ha sostenido una ideologia liberal, de defensa de la empresa privada, liberalización de la economia, privatización de las empresas estatales, estimulo al mercado, libre competencia económica, reprivatización del comercio exterior, de la banca y de la propiedad de la tierra. Las asociaciones empresariales y algunas profesionales se han pronunciado repetidamente a su favor, y to han presentado como la alternativa política más adecuada para el país. La base social, por consiguiente, la conforman dichas agnupaciones, que ven representados $y$ defendidos sus intereses en el partido ARENA $\rightarrow$ dado que la base social obrero-campesina orgánica es casi inexistente (Montes, 1988a: 101). A pesar de ello, una parte considerable de los sectores populares han votado por ARENA en las dos últimas elecciones, como se puede apreciar en los datos, manteniendo y reforzando su validez lo expresado después de las de 1988, ya que las citras apenas han variado - y a su favor- en ambas votaciones, con el agravante de que en las de 1989 se presentaba un grupo político (CD) que podía representar los intereses de sectores más populares:

"Sin embargo, en las últimas elecciones se puede percibir el grado de conciencia y de alienación de los integrantes de las clases sociales auxiliares y dominadas, de sus fracciones y capas o demás subdivisiones. En la medida en que sean válidos los datos correspondientes a cada una de las clases y fracciones (Montes, 1988a: 15-28), no se puede entender que el partido ARENA, representante de los intereses de la clase dominante, que cuenta entre un $0.3 \%$ y menos del $0.8 \%$ de la población, pueda obtener casi medio millón de votos el $48.1 \%$ de los válidos, $38.9 \%$ de los emitidos, y $17.9 \%$ de lodos los supuestamente posibles (cifras que superan incluso la suma de los integrantes de la clase fundamental dominante y de las capas medias) - a no ser que una elevada proporción de componentes de otras clases sociales, fracciones y subsectores (muchos de ellos pertenencientes a la clase fundamental dominada) se hayan plegado a esa opción ideológico-política ajena y contraria a su extracción de clase". (Montes, 1988a: 52). 


\subsection{PDC}

El partido Demócrata Cristiano, al igual que sus homólogos en otros paises, se inspira en la "doctrina social de la iglesia católica" elaborada hasta los años primeros de la década de los sesenta - fecha en que nace en El Salvador-; es decir, tiene una ideología de capitalismo moderado con mejor distribución de las ganancias y con diversas prestaciones sociales, pero se afinca en la propiedad privada, con mayor participación y distribución hacia las bases populares. Ello explica el reformismo y modiricación de las estructuras, que propugna e intenta aplicar, por to que aparece como izquierdizante para las clases y grupos dominantes, por más que en los paises desarrollados los partidos homologos se ubiquen a la derecha del espectro politico. Su base social se había expandido a los sectores medios, a la pequeha y mediana empresa, así como a amplios sectores populares de las grandes ciudades, en las que fácilmente ganaba las alcaldias, y de una buena parte del campesinado, no sólo por la formación de cuadros y por el trabajo de base, sino por el hecho de presentarse como un partido reformista que pudiera modificar las precarias condiciones de vida y desbloquear los cambios políticos. Una vez llamado a compartir el poder, tras el pacto con la Fuerza Armada, necesitaba ampliar su base social para ganar las elecciones ulteriores y consolidarse en el gobierno. Para ello buscaría "pactos sociales" y alianzas, primero con la Unidad Popular Democrática (UPD), articulación de organizaciones laborales obreras y campesinas, creada para tal tin (Montes, 1984: 51, 142-153) y, luego de debilitarse y disgregarse, haría algo similar con la Unión Nacional Obrero-Campesina (UNOC), para neutralizar a la recién nacida Unidad Nacional de los Trabajadores Salvadorenos (UNTS), contestataria y más a la izquierda que el PDC y sus bases sociales orgánicas (Montes, 1988a: 88-95, 96-100). También para el PDC estimo que es válido lo apuntado después de las elecciones de 1988, con mayor razón aún para las de 1989:

"Pero tampoco se entiende que el partido demócrata cristiano, exponente y representante de las "capas medias" -que en el mejor de los casos concentran entre el $10 \%$ y menos del $27 \%$ de la población-, haya podido obtener en las elecciones de 1985 más de medio millón de votos válidos (el $52.35 \%$ de los mismos), y en 1988 más de $300,000-35.1 \%$ de los válidos, $28.3 \%$ de los votos emitidos, y $13.1 \%$ de los supuestamente posibles-, a no ser que también algún porcentaje de los integrantes de la clase fundamental dominada, y alguna porción de los de las "capas medias" se supone han preferido al partido ARENA - haya sido víctima de la alienación de creer que un partido que responde a los intereses e ideología de 
las "capas medias" y del proyecto norteamericano puede atender a sus necesidades e intereses y resolver los problemas del país en beneficio de las grandes mayorlas - - i bien en las elecciones de 1988 se ha mostrado que el proceso y la experiencia bajo la conducción política de la democracia cristiana ha despertado cierta conciencia en los medios populares, a no ser que se haya profundizado la alienación de clase social en algunos de ellos que se hayan pasado a votar por ARENA, no para "agudizar las contradicciones", sino con la esperanza de encontrar ahí paliativos a su situación y a la crisis del pals". (Montes, 1988a: 52-53).

\subsection{PCN}

El Partido de Conciliación Nacional, desde su fundación en 1961 hasta el derrocamiento de su último gobierno el 15 de octubre de 1979, sostuvo una ideologla liberal, mezclada con intentos de leves reformismos para contener la creciente crisis y tensión social y mantenerse en el poder. Los intereses que defendia eran los de la clase dominante -en menor grado y en forma subordinada, los de los estratos superiores de las capas medias. Su base social estaba conformada por la clase dominante, la institución armada, núcleos importantes de grupos profesionales y empleados estatales, la organización paramilitar ORDEN, y todos los cuadros y bases del partido en el interior del país, votantes "olicialistas" y acreedores de favores y pequefios privilegios comparativos en el campo. En la presente década su base social se irá debilitando, conservando únicamente algunos cuadros en el interior y en algunas ciudades secundarias parte de la "clientela oficialista", románticos del partido y algunos pocos elementos "tradicionales". Pero la misma fluctuación ideológica, que ha ido variando en su discurso desde un neoliberalismo hasta una socialdemocracia, las divisiones internas y los relevos en la cúpula, junto con la incapacidad de recuperar el poder y gratificar a los seguidores, van convirtiendo al PCN en un resabio del pasado, en proceso de extinción -los diputados que ha obtenido en las últimas elecciones no los ha ganado con porcentajes completos, sino por residuos (Montes, 1988, 181-184).

\subsection{Otros}

En esta categoria se aglutina una serie de partidos minoritarios, no porque sean homogéneos en su ideologia y base social, sino porque entre todos ellos han obtenido menos votos que los tres anteriores; incluso los que han participado en las diversas elecciones no siempre han sido los mismos; pero ni cada uno de ellos, ni todos en conjunto, tienen posibilidades serias de acceso al poder - a lo más, a una cuota 
insignificante del mismo en la Asamblea Legislativa o en alguna alcaldia.

En las elecciones de 1982 participaron el PPS -partido de derecha, vinculado a una parte del capital, y de casi nula base sociał, y el POP - de ideología no muy definida y menor aún base social. (ECA, 1982, 324).

En 1984 participaron, además de los dos de las anteriores, los partidos MERECEN y PAISA, surgidos de escisiones en el PCN, con ideologla más de derecha que el partido matriz, nucleados en torno a personajes que pretendian hegemonizar el partido y aspirar a ser candidatos. También participó un partido nuevo, AD, surgido de un grupo de profesionales, principalmente abogados, como alternativa a los partidos politicos existentes, con una ideologla neoliberal en el contenido, pero que reclamaba en la forma una similitud a la socialdemocracia y aspiró a ser aceptada por la IS, aunque al final se articularla a la Internacional Liberal (ECA, 1984: 365).

En 1985 se agregaría a todos los anteriores el PAR, partido político que en otras décadas habla tenido ideologla progresista y bastante aceptación en el pueblo, considerado como una amenaza en 1967 por su platatorma de reformas económicas y sociales y por la amplia base social en algunas zonas del país. Sin embargo, luego dejó de participar en contiendas electorales, fue resucitado por personalidades sin mayor trayectoria política, y ofrecia una ideologia vacilante 0 ambigua en medio de la polarización del pais, lo que haría que no atrayera votos fuera de San Salvador, ni pudiera realizar trabajo de organización de cuadros y de captación de simpatizantes en el resto del pals (Montes, 1985: 223).

En 1988 se presenta a competir un nuevo partido, Liberación, surgido a consecuencia de una escisión en el seno de ARENA, por diferencias ideológicas y por rivalidades personales, pero manteniendo una ideología muy cercana al partido matriz, con alguna moderación en sus posiciones ideológicas y politicas. Participan todos los demás partidos menores de 1985, a excepción de PPS y MERECEN, más por los fracasos en elecciones anteriores, falta de fondos para la campaña, escasa o nula esperanza de alcanzar algún escaño en la Asamblea o algún municipio, que por deserción o disolución política (ECA, 1988: 285).

Antes de pasar a describir los partidos menores participantes en 1989, que presentó características peculiares y únicas, parece interesante reflexionar sobre los años anteriores. Todos estos partidos, además de tener muy escasa representación electoral, se ubican a la derecha del espectro ideológico y politico, ya sea por su origen o por 
haberse desgajado de partidos de esas caracteristicas, ya sea por sus declaraciones de principios y por sus plataformas programáticas, ya sea, sobre todo, por las alianzas que establecen con los partidos mayores. Desde 1982 todos los partidos formaron un bloque de oposición, liderado por ARENA, contra el PDC -incluso el PCN fue en alianza con ARENA a las elecciones de 1985-, con la excepción de AD que suscribió un pacto político con el PDC para obtener una pequena cuota de poder en el gobierno de este partido, y con la excepción también de los partidos mínimos que careclan de representación en la Asamblea (POP y PAR). El mismo PCN, a pesar de su discurso renovado y sus declaraciones progresistas, de hecho ha mantenido durante la mayor parte del perlodo alianzas con ARENA, y únicamente al final se ha acercado al PDC, posiblemente para neutralizar en parte el predominio hegemonizante de ARENA y su mayoría en la Asamblea Legislativa, más que por ideologla y convicción política. Como consecuencia de lo anterior, el espectro de los partidos políticos contendientes se extiende desde ARENA, en el extremo derecho, PPS, Liberación, PAISA, MERECEN, $P C N, A D$, hasta llegar al PDC en el extremo de la izquierda, no ideológica, sino relativa a los demás - quedando los partidos POP y PAR en una situación ambigua e irrelevante, pero ciertamente más próximos al PDC que al extremo opuesto. Todo ello facilita el que el PDC se forme una conciencia errónea de que es un partido de izquierda, que el resto lo considere como tal -en función, sobre todo, de la defensa de reformas impulsadas por él- y que se articule una alianza estratégica de todos los partidos contra el PDC, para disputarle el poder, debilitarlo en su ejercicio, e impedir que se consolide y perpetúe como grupo hegemónico político. El verlo y considerarlo así no es más que una ilusión óptica, derivada del hecho de que no se han tolerado partidos a la izquierda del espectro democrático; pero en realidad el PDC se ubica ideológicamente en el centro derecha, y más a su derecha estaría el resto de partidos políticos contendientes.

Las elecciones de 1989 introducirian elementos nuevos en el proceso iniciado en 1982. La derrota del PDC en 1988 frente a ARENA, unida a la disputa por la candidatura presidencial en su seno, llevó a una escisión del partido, desgajándose un grupo que vino a unirse con MERECEN para formar el Movimiento Auténtico Cristiano (MAC), no tanto por diferencias ideológicas cuanto por rivalidades personales y lucha de poder interno. La polarización creciente, la inviabilidad de oportunidades en unas elecciones presidenciales en que la disputa se centraba en los dos grandes partidos, haria que tres de los menores (Liberación, PAISA y PPS) compitieran juntos en la denominada Unidad Popular (UP), buscando medir el respaldo que conservaban en el 
electorado, y fundamentar posibles alianzas y cuotas de poder. El recién fundado Partido Social Demócrata (PSD) se alió con el Movimiento Nacional Revolucionario (MNR) y con el Movimiento Popular Social Cristiano (MPSC) -ambos integrantes del Frente Democrático Revolucionario (FDR), aliado estratégico del FMLN-, conformando la Convergencia Democrática (CD). Competirlan por separado, además de los tres partidos mayores, y las alianzas ya indicadas, el PAR y AD —este último reconciliado con el PDC y con un nuevo pacto político, aunque deseoso de cuantificar los simpatizantes que aún le apoyan. EI PDC, por otro lado, buscó ampliar su base social y política, en alianza con el sector "independiente", del que seleccionaría su candidato a vicepresidente de la república. En conclusión, para las elecciones de 1989 se amplió el espectro político, participando opciones a la izquierda del PDC, dando con ello no sólo una gama más diversificada de posibilidades, sino también una apertura $\longrightarrow$ sensación de ella- mayor que en anos anteriores (Montes, 1989: ECA 1989: 271).

A lo anterior hay que agregar un elemento cualitativamente nuevo y distinto: la propuesta del FMLN presentada el 23 de enero de 1989. Después de presentar una serie de condiciones, para aceptar el resultado de las elecciones si se postergan, el FMLN se compromete, entre otras cosas a:

4. "Llamaria a toda su base social a participar en la actividad electoral, convocando a todo el pueblo a votar y a respaldar la plataforma y candidatos de la Convergencia Democrática". (ECA, 1989: 133).

La CD, por consiguiente, en la coyuntura del momento, no sólo representaria su ideologia y proyecto político propio, a la izquierda del PDC, sino que al mismo tiempo asumirla la representación política vicaria del FMLN en las elecciones de septiembre. Con ello, la gama y el espectro politico se abriria al extremo de la izquierda -aunque ésta no participara directamente ni presentara sus propios candidatos. En la siguiente propuesta del FMLN, firmada el 6 de abril de 1989, después de las elecciones de marzo y del triunfo electoral en la primera vuelta por parte de ARENA, ya no serla en el futuro la CD quien lo representarla, sino que participarlan directamente con su propia plataforma y candidatos:

"EI FMLN particiaprla directamente como fuerza política en esas elecciones con su bandera y en coalición con otros partidos que estuvieran dispuestos a participar junto a nosotros". (ECA, 1989: 404). 
Con ello se completaria el espectro politico, asi como las exigencias de los poderes fácticos nacionales y extranjeros de que el FMLN renuncie a la lucha por el poder a través de la vía militar, y se incorpore al proceso democrático del país. Pero mientras no se llegue a ese momento, es dificil medir y cuantificar la base popular que lo sustenta.

Tampoco se ha podido comprobar de manera confiable el respaldo popular y la aceptación que pueda tener la $C D$, dadas las circunstancias que rodearon las elecciones de marzo de 1989, en las que la frustración de gran parte de la población, unida a la instrucción girada por el FMLN de abstenerse de ir a votar - más la parte proporcional, por mínima que sea, derivada del paro al transporte y de otras acciones armadas. En otro lugar se ha hecho el intento de explicación y análisis de los hechos (Montes, 1989: 199-210).

\section{Recapltulación}

A lo largo de estos siete años, y a través de cinco elecciones sucesivas, no sólo se ha ido consolidando el "proceso democrático formal", sino que se ha ido librando una lucha por una cuota limitada de poder, en la que han participado siempre partidos grandes, de ideologia consistente, representantes y defensores de sectores e intereses poderosos en el pais, a la par de otros partidos menores o insignificantes, que ofrecen pequekas variaciones ideológico-políticas, y ninguna alternativa cualitativamente distinta o viable. El proceso ha ido avanzando, hasta el punto de que en 1989 se ha ampliado la gama de partidos hasta la inclusión de una alianza de izquierda moderada y democrática; cerca se estuvo de que el proceso tomara un rumbo cualitativamente nuevo y distinto, con la inclusión de todas las opciones políticas del pais, de haberse aceptado y/o negociado la propuesta del FMLN del 23 de enero de 1989.

La ausencia de partidos y expresiones políticas representativos y orgánicos de las clases subalternas y dominadas, lleva en todas estas elecciones a que una buena parte de la población perteneciente a los sectores populares, o se abstenga de votar, o tenga que elegir en el estrecho mercado de la oferta partidaria - ya sea por una alienación profundamente introyectada, ya sea por la carencia de proyectos políticos e ideologías más cercanos a sus intereses. El resultado es que se aprecia una llamativa distorsión entre la estructura social del país y los resultados de las elecciones.

Sin embargo, la crisis del pais y el problema fundamental no se ha resuelto con ello, viniendo a confirmar la tesis planteada antes de iniciarse el proceso electoral y al inicio de este trabajo, de que si no se 
lo aborda, no puede resolverse con este instrumento inadecuado para ello. El objetivo fundamental que se proponen las repetidas elecciones es deslegitimar al FMLN, por medio de una masiva participación del pueblo, y asi poder hacerle la guerra sin limitaciones ni excusas, facilitando la ayuda a un gobierno legitimo y "democrático". Queda en pie que es nada más una exigua cuota de poder la que se ha devuelto al pueblo, para que la entregue a las personas que libremente eligiera. El verdadero poder $\longrightarrow$ la parte más importante y decisoria del mismono se le ha entregado al pueblo para que decida sobre él, no se le ha devuelto ni restaurado su soberania.

En las elecciones se disputa una cuota del poder civil confiada a la administración de los partidos políticos; y ellos son los que compiten por conquistarla o repartírsela. Pero hay poderes fundamentales que no participan en las elecciones, si no es en forma indirecta: la institución armada y la administración norteamericana. En 1982 el veto impuesto directamente por la administración norteamericana, e indirectamente por la institución armada como su instrumento de ejecución, burlaria los resultados electorales para imponer un gobierno que no habia sido expresión de los votantes (ECA, 1982: 233-258). El rechazo sistemático de la administración norteamericana a que D'Aubuiisson llegara a ser presidente de la república forzó un cambio de liderazgo y de candidato en ARENA. La obstinación de Reagan y su equipo de asesores en impedir cualquier negociación con el FMLN, o la participación de éste en el poder político de El Salvador, bloquearia el avance hacia una solución política. Por su parte, la institución armada no permitiria al poder civil que se inmiscuyera en la dirección de la guerra, impusiera personas en la cúpula militar o reestructurara a ésta contra sus intereses, condicionara los diálogos con el FMLN, las treguas o ceses al fuego, la salida de lisiados de guerra insurgentes, o la aceptación de la propuesta del 23 de enero de 1989; la insurrección del coronel Ochoa en Cabafias contra el Ministro de Defensa, o el conflicto surgido con ocasión del nombramiento del nuevo Ministro de Defensa del gobiemo de ARENA, serian algunos indicadores de la autonomía relativa de la institución armada frente al poder civil. Estos poderes reales no son entregados al pueblo. no se cuestionan en las elecciones que se repiten rutinariamente. $Y$ como tampoco son partidos politicos que se enfrenten a la consulta popular para validar y legitimar su función y su desempeño, unos poderes tan importantes y tan decisorios como ésos no entran al debate político, y son escamoteados a la soberanía popular, que no puede decir su palabra ni otorgar su voto, o su veto.

San Salvador, 22 de julio de 1989. 


\section{Anexo}

\section{Cuadro I}

Elecclones para diputados (Asamblea constituyente). 1982

Por departamento y partidos

\begin{tabular}{lrrrrrrrrrr}
\hline Depto & PDC & ARENA & PCN & OTROS & Validos & No-Val. & \%/Emit. & Emitidos & $\%$ \\
\hline San Salvador & 145.076 & $\mathbf{8 7 . 8 6 1}$ & $\mathbf{3 7 . 9 5 4}$ & 59.202 & 330.093 & 45.745 & 12.17 & 375.838 & 24.36 \\
Santa Ana & 67.851 & 39.909 & 24.687 & 20.198 & 152.645 & 22.345 & 12.77 & 174.990 & 11.34 \\
San Miguel & 42.049 & $\mathbf{3 1 . 8 3 4}$ & 29.170 & 8.651 & 111.704 & 13.602 & 10.86 & 125.306 & 8.12 \\
La Libertad & 65.453 & 46.653 & 23.881 & 19.247 & 155.234 & 24.385 & 13.58 & 179619 & 11.64 \\
Usulután & 18.089 & 18.219 & 10.084 & 5.803 & 52.195 & 6.608 & 11.24 & $\mathbf{5 8 . 8 0 3}$ & 3.81 \\
Sonsonate & 47.977 & 37.783 & 20.926 & 11.051 & 117.737 & 15.710 & 11.77 & 133.447 & 8.65 \\
La Unión & 24.513 & 19.734 & 23.637 & 4.579 & 72.463 & 7.849 & 9.77 & 80.312 & 5.20 \\
La Paz & 31.931 & 21.627 & 17.930 & 6.087 & 77.565 & 12.283 & 13.67 & 89.848 & 5.82 \\
Chalatenango & 17.694 & 15.506 & 10.619 & 2.902 & 46.721 & 6.883 & 12.84 & 53.604 & 3.47 \\
Cuscatlán & 15.977 & 23.734 & 12.227 & 4.311 & 56.249 & 10.648 & 15.92 & 66.897 & 4.34 \\
Ahuachapán & 27.723 & 23.605 & 12.746 & 4.059 & 68.133 & 11.860 & 14.83 & 79.993 & 5.18 \\
Morazán, & 13.684 & 8.239 & 7.874 & 2.039 & 31.836 & 4.034 & 11.25 & 35.870 & 2.32 \\
San Vicente & 14.599 & 8.146 & 11.741 & 3.000 & 37.486 & 6.726 & 15.21 & 44.212 & 2.87 \\
Cabańas & 10.534 & 12.236 & 14.829 & 1.059 & 39.658 & 5.754 & 12.67 & 45.412 & 2.94 \\
\hline Totales & 543.150 & 395.086 & 258.305 & 152.188 & 1.348 .729 & 194.432 & 12.60 & 1.543 .161 & 100 \\
& $(40.27 \%)$ & $(29.29 \%)$ & $(19.15 \%)$ & $(11.28 \%)$ & $(100 \%)$ & & & & \\
\hline
\end{tabular}

Fuente:ECA, abril 1982: 324. 
Cuadro II

Elecciones presidenciales (1a. vuelta). 25 marzo 1984

Por departamento y partidos

\begin{tabular}{lrrrrrrrrr}
\hline Depto & PDC & ARENA & PCN & OTROS & Valldos & No-Val. & \%/Emit. & Emitidos & $\%$ \\
\hline San Salvador & 205.381 & 101.834 & 44.701 & 34.415 & 386.331 & 41.133 & 9.62 & 427.464 & 29.92 \\
Santa Ana & 66.832 & 41.781 & 26.368 & 9.179 & 144.160 & 17.188 & 10.65 & 161.348 & 11.29 \\
San Miguel & 27.048 & 18.770 & 19.142 & 6.143 & 71.103 & 7.487 & 9.53 & 78.590 & 5.50 \\
La Libertad & 65.024 & 48.792 & 23.797 & 10.389 & 148.002 & 21.967 & 12.92 & 169.969 & 11.90 \\
Usulután & 20.708 & 19.184 & 19.932 & 6.345 & 66.169 & 8.906 & 11.86 & 75.075 & 5.25 \\
Sonsonate & 47.921 & 35.448 & 20.517 & 7.802 & 111.688 & 14.146 & 11.24 & 125.834 & 8.81 \\
La Unión & 13.465 & 7.129 & 13.900 & 2.005 & 36.499 & 4.999 & 12.05 & 41.498 & 2.90 \\
La Paz & 26.306 & 22.050 & 15.530 & 5.132 & 69.018 & 12.001 & 14.81 & 81.019 & 5.67 \\
Chalatenango & 12.741 & 8.963 & 7.979 & 1.634 & 31.322 & 6.664 & 17.54 & 37.986 & 2.66 \\
Cuscatlán & 11.509 & 18.544 & 11.158 & 2.817 & 44.028 & 6.371 & 12.64 & 50.399 & 3.53 \\
Ahuachapán & 24.299 & 23.763 & 16.954 & 3.626 & 68.642 & 9.211 & 11.83 & 77.853 & 5.45 \\
Morazán & 9.059 & 5.939 & 8.077 & 1.582 & 24.652 & 3.914 & 13.70 & 29.566 & 2.07 \\
San vicente & 11.853 & 11.590 & 8.032 & 2.096 & 33.571 & 4.564 & 11.97 & 38.135 & 2.67 \\
Cabañas & 7.581 & 13.130 & 8.469 & 1.911 & 31.091 & 3.867 & 11.06 & 34.958 & 2.45 \\
\hline Totales & 549.727 & 376.917 & 244.556 & 95.076 & 1.266 .276 & 162.418 & 11.37 & 1.428 .694 & 100 \\
& $(43.41 \%)$ & $(29.77 \%)$ & $(19.31 \%)$ & $(7.51 \%)$ & $(100 \%)$ & & & &
\end{tabular}

Fuente: CCE; tomado de ECA, abril-may o 1984: 365.

Digitalizado por Biblioteca "P. Florentino Idoate, S.J."

Universidad Centroamericana José Simeón Cañas 


\section{Cuadro III}

Elecciones para diputados. 1985

Por departamento y partidos

\begin{tabular}{lrrrrrrrrr}
\hline Depto & PDC & ARENA & PCN & OTROS & Validos & No-Val. & \%/Emit. & Emitldos & $\%$ \\
\hline San Salvador & 148.985 & 70.650 & 11.404 & 30.686 & 261.725 & 30.683 & 10.5 & 292.408 & 26.4 \\
Santa Ana & 58.958 & 33.093 & 11.330 & 9.186 & 112.567 & 16.032 & 12.5 & 128.601 & 11.6 \\
San Miguel & 32.339 & 13.288 & 6.573 & 4.074 & 56.274 & 7.936 & 12.4 & 64.210 & 5.8 \\
La Libertad & 54.901 & 33.490 & 7.162 & 8.315 & 103.868 & 17.774 & 14.6 & 121.642 & 11.0 \\
Usulután & 28.761 & 15.016 & 5.988 & 7.216 & 56.981 & 9.268 & 14.0 & 66.249 & 6.0 \\
Sonsonate & 42.312 & 31.704 & 4.084 & 6.884 & 84.984 & 11.769 & 12.2 & 96.753 & 8.7 \\
La Unión & 17.959 & 4.932 & 5.332 & 2.753 & 30.976 & 4.903 & 13.7 & 35.876 & 3.2 \\
La Paz & 25.237 & 17.418 & 6.082 & 5.858 & 54.595 & 8.530 & 13.5 & 63.125 & 5.7 \\
Chalatenango & 22.903 & 11.169 & 4.235 & 2.143 & 40.450 & 7.542 & 15.7 & 47.992 & 4.3 \\
Cuscatlán & 13.823 & 15.588 & 4.193 & 4.382 & 37.986 & 6.639 & 14.9 & 44.625 & 4.0 \\
Ahuachapán & 24.104 & 17.471 & 5.757 & 4.368 & 51.700 & 8.528 & 14.2 & 60.228 & 5.4 \\
Morazán & 10.061 & 4.759 & 1.924 & 1.705 & 18.449 & 3.270 & 15.1 & 21.719 & 2.0 \\
San Vicente & 15.357 & 9.313 & 2.480 & 2.234 & 29.384 & 4.457 & 13.2 & 33.841 & 3.1 \\
Cabanas & 9.638 & $\mathbf{8 . 7 7 4}$ & 4.186 & 2.894 & 25.292 & 4.908 & 16.3 & 30.200 & 2.7 \\
\hline Totales & 505.338 & 286.665 & 80.730 & 92.498 & 965.231 & 142.241 & 12.8 & 1.107 .472 & 100 \\
& $(52.35 \%)$ & $(29.70 \%)$ & $(8.36 \%)$ & $(9.53 \%)$ & $(110 \%)$ & & & & \\
\hline
\end{tabular}

Fuente: CCE; tomado de Montes, en ECA, abril 1985: 223, marzo-abil 1988: 184. 


\section{Cuadro IV}

Elecciones PARA DIPUTADOS. 1988

Por departamento y partidos

\begin{tabular}{lrrrrrrrrr}
\hline Depto & PDC & ARENA & PCN & OTROS & Valldos & No-Val. & \%/Emit. & Emltidos & $\%$ \\
\hline San Salvador & 86.463 & 123.663 & 10.364 & 28.304 & 248.776 & 52.983 & 17.6 & 301.759 & 26.2 \\
Santa Ana & 31.071 & 40.277 & 10.513 & 8.245 & 90.106 & 19.200 & 17.6 & 109.306 & 9.5 \\
San Miguel & 24.841 & 30.403 & 7.807 & 3.017 & 66.068 & 11.276 & 14.6 & 77.344 & 6.7 \\
La Libertad & 36.597 & 52.472 & 7.294 & 9.080 & 105.643 & 34.018 & 24.4 & 139.661 & 12.1 \\
Usulután & 18.186 & 28.778 & 4.820 & 1.832 & 53.616 & 16.895 & 24.0 & 70.511 & 6.1 \\
Sonsonate & 28.953 & 39.952 & 7.726 & 8.454 & 85.058 & 14.444 & 14.5 & 99.502 & 8.6 \\
La Unión & 15.286 & 15.109 & 3.499 & 208 & 34.102 & 17.140 & 33.4 & 51.242 & 4.5 \\
La Paz & 14.922 & 23.424 & 4.908 & 4.265 & 47.519 & 11.699 & 19.8 & 59.208 & 5.1 \\
Chalatenango & 14.677 & 13.749 & 3.152 & 4.444 & 36.022 & 7.594 & 17.4 & 43.616 & 3.8 \\
Cuscatlán & 10.046 & 20.867 & 3.063 & 1.416 & 35.439 & 8.347 & 19.1 & 43.786 & 3.8 \\
Ahuachapán & 14.742 & 21.634 & 6.641 & 4.122 & 47.139 & 9.369 & 16.6 & 56.508 & 4.9 \\
Morazán & 11.949 & 11.051 & 4.721 & 580 & 28.301 & 7.604 & 21.2 & 35.905 & 3.1 \\
San Vicente & 12.439 & 14.428 & 1.401 & 2.234 & 30.502 & 5.541 & 15.4 & 36.043 & 3.1 \\
Cabañas & 6.544 & 11.889 & 2.665 & 1.360 & 22.458 & 4.155 & 15.6 & 26.613 & 2.3 \\
\hline Totales & 326.716 & 447.696 & 78.756 & 77.581 & 930.749 & 220.185 & 19.1 & 1.150 .934 & 100 \\
& $(34.95 \%)$ & $(47.89 \%)$ & $(8.42 \%)$ & $(8.30 \%)$ & $(100 \%)$ & & & & \\
\hline
\end{tabular}

Fuente: CCE; tomado de Montes, en ECA, marzo-abril 1988: 183-194, marzo 1989: 205. 
Cuadro V

Elecclones presidenclales. 1989

Por departamento y partidos

\begin{tabular}{lrrrrrrrrrr}
\hline Depto & PDC & ARENA & PCN & OTROS & Valldos & No-Val. & \%/Emlt. & Emltidos & $\%$ \\
\hline San Salvador & 97.252 & 147.691 & 5.962 & 24.261 & 275.166 & 13.059 & 4.5 & 288.225 & 28.7 \\
Santa Ana & 35.050 & 47.136 & 5.512 & 6.213 & 93.911 & 7.327 & 7.2 & 101.238 & 10.1 \\
San Miguel & 22.917 & 30.913 & 2.451 & 2.168 & 58.449 & 3.367 & 5.4 & 61.816 & 6.2 \\
La Libertad & 35.320 & 58.776 & 3.789 & 6.821 & 104.706 & 7.448 & 6.6 & 112.154 & 11.2 \\
Usulután & 14.953 & 26.469 & 2.165 & 1.980 & 45.567 & 3.490 & 7.1 & 49.057 & 4.9 \\
Sonsonate & 37.525 & 46.340 & 3.644 & 3.454 & 90.963 & 7.327 & 7.5 & 98.290 & 9.8 \\
La Unión & 16.286 & 16.114 & 1.416 & 1.250 & 34.782 & 2.780 & 7.4 & 37.562 & 3.7 \\
La Paz & 13.836 & 25.125 & 1.782 & 1.934 & 42.677 & 3.071 & 6.7 & 45.748 & 4.6 \\
Chalatenango & 10.852 & 14.058 & 1.765 & 1.672 & 28.297 & 2.265 & 7.4 & 30.562 & 3.0 \\
Cuscatlán & 8.266 & 24.280 & 1.443 & 1.881 & 35.870 & 2.748 & 7.1 & 38.618 & 3.8 \\
Ahuachapán & 20.645 & 28.882 & 4.022 & 3.021 & 56.570 & 5.018 & 8.1 & 61.588 & 6.1 \\
Morazán & 8.244 & 10.804 & 2.222 & 1.033 & 22.303 & 2.747 & 11.0 & 25.050 & 2.5 \\
San vicente & 11.579 & 15.518 & 864 & 932 & 28.893 & 1.890 & 6.1 & 30.783 & 3.1 \\
Cabañas & 5.644 & 13.264 & 1.181 & 835 & 20.924 & 1.538 & 6.8 & 22.462 & 2.2 \\
\hline Totales & 338.369 & 505.370 & 38.218 & 57.121 & 939.078 & 64.075 & 6.4 & 1.003 .153 & 100 \\
& $(36.03 \%)$ & $(53.82 \%)$ & $(4.07 \%)$ & $(6.08 \%)$ & $(100 \%)$ & & & &
\end{tabular}

Fuente: CCE; tomado de Montes, en ECA, marzo 1989: 206. 


\section{Blbllografla utllizada:}

Boletin de Ciencias Económicas y Sociales; "Las elecciones en El Salvador"; marzo-abril 1982: 301-320 (número especial); San Salvador, UCA.

ECA, "Las elecciones y la unidad nacional: diez tesis criticas" (Editorial); abril 1982: 233-258; San Salvador, UCA.

ECA, "Resultados electorales por departamento" (documentación); abril 1982: 324.

ECA, "Resultados oficiales del Consejo Central de Elecciones" (documentación); abril-mayo 1988: 285.

ECA, "Propuesta del FMLN para convertir las elecciones en una contribución a la paz" (documentación); en.-feb. 1989: 133-134.

ECA, "Resultados oficiales de las elecciones" (documentación); marzo 1989: 271.

ECA, "Posición del FMLN trente al futuro gobierno de ARENA y propuesta para alcanzar una democracia real, una nueva sociedad y la paz" (documentación); abril-mayo 1989: 403-405.

IUDOP; "Las elecciones presidenciales y la oferta del FMLN"; San Salvador, UCA, No. 20, marzo de 1989.

IUDOP, "Expectativas de los salvadoreños sobre el gobierno de ARENA"; San Salvador, UCA, mayo de 1989a (Boletín de prensa).

Montes, Segundo; "Las elecciones y el poder en El Salvador"; en rev. ECA, en.fob. 1982: 59-66.

Montes, Segundo; El Salvador: las fuerzas sociales en la presente coyuntura (enero 1980 a diciembre 1983); San Salvador, UCA, 1984.

Montes, Segundo; "Las elecciones del 31 de marzo"; en rev. ECA, abril 1985: 215-118.

Montes, Segundo; "Las elecciones del 20 de marzo de 1988"; en rev. ECA, marzo-abril 1988: 175-190.

Montes, Segundo; El Salvador 1988. Estructura de clases y comportamiento de las fuerzas sociales; San Salvador, UCA 1988a.

Montes, Segundo; "Las elecciones presidenciales del 19 de marzo de 1989; en rev. ECA, marzo 1989: 199-210. 